PressAcademia Procedia

4th Global Business Research Congress, May 24-25, 2018, Istanbul, Turkey.

\title{
LINKING PERCEIVED ORGANIZATIONAL JUSTICE TO JOB SATISFACTION ORGANIZATIONAL COMMITMENT AND ORGANIZATIONAL CITIZENSHIP BEHAVIORS: THE MODERATOR ROLE OF MINDFULNESS
}

DOI: 10.17261/Pressacademia.2018.894

PAP- V.7-2018(47)-p.263-267

Bora Yildiz ${ }^{1}$, Alptekin Develi ${ }^{2}$

${ }^{1}$ Istanbul University, Faculty of Economics, Department of Business Administration, Beyazit/Fatih, Istanbul, Turkey. borayildiz@istanbul.edu.tr, ORCID: 0000-0002-0373-6457

${ }^{2}$ Tokat Gaziosmanpasa University, Resadiye Vocational School, Tokat, Turkey. alptekin.develi@gop.edu.tr, ORCID: 0000-0001-7232-5603

To cite this document

Yildiz, B., Develi, A. (2018). Linking perceived organizational justice to job satisfaction, organizational commitment, and organizational citizenship behaviors: the moderator role of mindfulness. Press Academia Procedia (PAP), V.7, p.263-267.

Permemant link to this document: http://doi.org/10.17261/Pressacademia.2018.894

Copyright: Published by PressAcademia and limited licenced re-use rights only.

\section{ABSTRACT}

Purpose- Grounded in Social Cognitive Theory (Bandura, 2001) and Social Exchange Theory (Blau, 1964), the purpose of this study is to investigate the mediating effects of job satisfaction and organizational commitment on the employees' perceived organizational justiceorganizational citizenship behaviors relationship, and the moderator role of mindfulness by theoretically.

Methodology- Building from the robust theories and following the prior literature, in this paper, we develop a conceptual model that could be examined by using PROCESS macro with a moderated mediation analysis.

Findings- This article offers a novel theoretical model that is possible to test it by empirically.

Conclusion- As a result of this study, we have contributed to the existing literature in two ways; a) by using moderated mediation analysis we attracted attention to the moderator role of mindfulness, and b) we tried to requestion of the existing well established relations among the variables that in the mediation equation.

Keywords: Job satisfaction, organizational commitment, mindfulness, organizational citizenship behavior, organizational justice JEL Codes: M10, M12, M54

\section{ALGILANAN ÖRGÜTSEL ADALET, iş TATMINI, ÖRGÜTSEL BAĞLILIK VE ÖRGÜTSEL VATANDAŞLIK DAVRANIŞI ILIŞKISI: BİLINÇLI FARKINDALIĞIN DÜZENLEYICI ROLÜ}

\section{ÖZET}

Amaç- Bu araştırma ile Sosyal Bilişsel Teori (Bandura, 2001) ve Sosyal Mübadele Teorisi (Blau, 1964) teorilerine dayanarak çalışanların örgütsel adalet algısı ve örgütsel vatandaşlık davranışları ilişkisinde iş tatmini ve örgütsel bağlılığın aracılık etkisi ve tüm bu ilişkilerde bilinçli farkındalığın düzenleyici rolü teorik olarak incelenmiştir.

Yöntem- Bu çalışmada, güçlü teorilerden ve ilgili literatürden yola çıkılarak, PROCESS makro yazılımı üzerinden durumsal indirekt etki ilişkisinin incelenebileceği kavramsal bir model geliştirilmiştir.

Bulgular- Bu çalışma ile deneysel olarak test edilebilicek bir araştırma modeli önerilmiştir.

Sonuç- Bu çalışmanın sonucunda, mevcut literatüre iki anlamda katkı sağlandığı düşünülmektedir; a) durumsal indirekt etki analizi kullanılarak bilinçli farkındalığın düzenleyici rolüne dikkat çekilmiştir, b) Yazında zaten var olan ve oturmuş olan aracı etki denklemindeki değişkenler arasındaki ilişki yeniden sorgulanmıştır.

Anahtar Kelimeler: İş tatmini, örgütsel bağlılık, bilinçli farkındalık, örgütsel vatandaşlık davranışı, örgütsel adalet. JEL Kodları: M10, M12, M54 


\section{GiRiş}

Sosyal Bilişsel Teori (Bandura, 2001), bilişsel-davranışsal bir yaklaşımla insanların nasıl düşündüğü ve nasıl hareketler sergilediği arasındaki etkileşime değinmektedir (Bahn, 2001). Teori, öğrenme süreci ekseninde, insan davranışlarının bireysel, davranışsal ve çevresel etkilerden kaynaklandığını ileri sürmektedir (Bandura, 2001). Sosyal Bilişsel Teorinin örgütlerdeki etkisi; bireysel değişiklik, bilişsel değişiklik, hatalardan öğrenme ve davranışlarda değişiklik şeklinde görülmektedir (Bandura, 2002). Diğer yandan Sosyal Mübadele Teorisi (Blau, 1964) ise, kişinin kendi beklentileri doğrultusunda bireysel olarak yaptığı fayda-maliyet analizi sonucunda akılcı bir karar verme sürecini ifade eder (Emerson, 1976). Bu teoriye göre, kişilerin davranışları kendi algı ve tutumlarına göre değişmektedir. Başka bir ifadeyle, kişinin davranışları kendi algıları ve tutumları sonucunda oluşmaktadır (Blau, 1964). Sosyal Mübadele Teorisi; çalışanların, örgüt tarafından sağlanan ekonomik ve sosyal yararlar karşılığında, emek ve sadakatlerini değiştirmeye hazır olduklarını göstermektedir (Cropanzano ve Mitchell, 2005).

Örgütsel adalet, örgütsel işleyişe yönelik dağıtımsal, ilişkisel ve süreçlere ilişkin hakkaniyet algısını; iş tatmini, yapılan işe yönelik duyulan olumlu veya olumsuz memnuniyet düzeyini; örgütsel bağılıık, örgüte yönelik farklı motivleri olan bir kalma isteğini; örgütsel vatandaşlık davranışı, örgütün iyi oluşuna katkı sağlayan karşııksız ve gönüllü davranışları ve son olarak bilinçli farkındalık da istekli dikkatlilik göstermeyi ifade etmektedir. Bu değişkenlerden oluşan yapı dikkate alındığında, Sosyal Bilişsel Teori ve Sosyal Mübadele Teorisinin söz konusu değişkenler arasındaki ilişkileri açıklayan kuramsal temelleri teşkil ettikleri söylenebilir.

Literatürde pekçok çalışmada örgütsel adalet, iş tatmini, örgütsel bağlıık ve örgütsel vatandaşlık davranışı konuları ayrı ayrı veya en fazla üç değişkenden oluşan modellerle incelenmiştir. Buna ek olarak ilgili literatür incelendiğinde söz konusu bu değişkenlerin birbirleriyle önemli derecede ilişkili değişkenler olduğu geçmiş araştırmalarca ortaya konmuştur. Ancak önceki çalışmalardan farklı olarak bu araştırmada bilinçli farkındalığın literatürde oturmuş olan bu ilişkisel modelleri ıımlaştıııı (moderator) bir etkisinin olduğu öngörülmüştür. Başka bir ifade ile bu araştırma ile dikkat çekilmek istenen ana araştırma sorusu şöyledir; Örgütsel adalet, örgütsel bağlılık, iş tatmini ve örgütsel vatandaşıık davranışları arasındaki indirekt ve pozitif yöndeki ilişkiler bilinçli farkındalı̆̆ı yüksek olan çalışanlar da mı geçerlidir?

Yukarıdaki açıklamalara binaen bu çalışmada, Sosyal Bilişsel Teori (Bandura, 2001) ve Sosyal Mübadele Teorisi'ne (Blau, 1964) dayanarak örgütsel adalet, iş tatmini, örgütsel bağlıık, örgütsel vatandaşıı davranışı ve bilinçli farkındalık konularıyla ilgili literatürden hareketle bir araştırma model önerisi geliştirilmiş ve bu modeli test edebilmek için bir yöntem önerilmiştir.

\section{LITERATÜR INCELEMESI VE DEĞişKENLER ARASI ILIŞSKILER}

\section{Örgütsel Adalet}

Örgütsel adalet, çalışanların örgütteki iş ve uygulamara yönelik olan adalet algılamalarını ifade eder (Judge ve Colquitt, 2004). Başka bir deyişle, örgütsel adalet, çalışanların işle ilgili adaleti nasıl algıladıklarını ve buna karşılık nasıl tepkiler verdiklerini anlatır (Aryee, Budhwar ve Chen, 2002)

Örgütsel adaletin üç farklı türü bulunmaktadır. Bu türler dağıtım adaleti, prosedür adaleti ve etkileşim adaleti şeklindedir. Dağıtım adaleti: Maaş, ücret artışı, promosyon, prim ve sosyal haklar gibi örgütsel çıktıların adil bir şekilde dağıtılmasına yönelik olan adalet algısını ifade eder (Colquitt, LePine, Piccolo ve Zapata, 2012; Chambers, 2002). Prosedür adaleti: kazanılmış hakların ve verilecek kararların belirlenmesindeki prosedür, süreç ve yönteme yönelik adalet algısını temsil eder (Luo, 2009). Etkileşim adaleti ise çalışanların prosedürlerin gerçekleştiği süreçte şahit oldukları tutum ve davranışlara yönelik bireylerarası davranışlardan kaynaklanan adalet algısını ifade eder (Bies ve Moag, 1986).

\section{Örgütsel Vatandaşlık Davranışı}

Örgütsel vatandaşlık davranışı (ÖVD), tanımlanan standartların ve iş gereklerinin ötesine geçerek gösterilen gönüllü emekleri, başka bir ifadeyle, rol fazlası davranışları ifade eder (Smith, Organ ve Near, 1983). ÖVD; resmi iş tanımlarının ötesine geçen, tanımlanmıs rol gereklerini aşan ve resmi olarak ödüllendirilmeyen veya yine aynı şekilde cezalandırılmayan ancak yine de çalışanlar tarafından sergilenen ve örgütsel verimliliğe katkı sağlayan davranışlar olarak tanımlanabilir (Schnake ve Dumler, 2003).

Literatürdeki genel kabul görmüş sınıflandırmaya göre ÖVD beş boyuttan oluşmaktadır. Bu boyutların isimleri; diğergamlık, vicdanlılık, sivil erdem, centilmenlik ve nezaket şeklindedir. Diğergamlık, herhangi bir sorun yaşayan iş arkadaşlarına yardım etme amaçlı gösterilen davranışlardır. Vicdanlıık, iş gerekleri anlamında en az düzeyde beklenen rol davranışlarının ötesine geçmeye istekli olmaya yönelik davranışlardır. Sivil erdem, örgütün politik yaşamına aktif ve sorumlu bir şekilde katılmaya gönüllü olma davranışlarıdır. Centilmenlik, gerginliğe neden olabilecek hareketler ve şikayetçilikten kaçınma ve imtiyazı olmaya yönelik davranışlardır. Nezaket ise, birbirlerinin yaptıkları işlerden ve aldıkları kararlardan etkilenen çalışanların bunları iş arkadaşlarına danışarak yapması suretiyle gösterdikleri olumlu davranışlardır (Organ, 1990; Wang, Hinrichs, Prieto ve Howell, 2013; Podsakoff, MacKenzie, Paine ve Bachrach, 2000; Koys, 2001).

\section{Aracı Değişken: İ̧̧ Tatmini}

iss tatmini, işgörenlerin çalışma şartlarına veya mesleklerine yönelik duydukları olumlu ve olumsuz düşüncelerin bir toplamını ifade eder (Spector, 1997). Başka bir ifadeyle, iş tatmini, çalışanların sorumlusu oldukları rollere ilişkin duygusal uyumları olarak tanımlanabilir (Vroom, 1964). İş tatmini, çalışanların işleriyle ilgili olumlu ve olumsuz görüşlerinin oluşturduğu bir bütünü açıklar. Bunun yanı sıra, iş tatmini, çalışanların örgütlerinden neler bekledikleri ve bu beklentilerin ne kadarının karşılandığı ortaya koyar (Davis ve Newstorm, 1985).

Bu bağlamda, iş tatmini, çalışanların işlerinden duydukları kazanımların içsel motivasyonlarına ne derece etki gösterdiğini ifade eder (Hackman ve Oldham, 1976). İş tatmini, işyerinde çalışanların sergilediği davranışları doğrudan etkileyen bir kavramdır ve organizasyonların etkinliği ve verimliliği için ele alınması gereken en önemli faktörlerden biridir (Azırı, 2011). 
Sosyal Mübadele Teorisine dayanarak çalışanların kurumlar içerisindeki mübadele işlemleri ile ilgili bir karşılıklılık ilişkisi içerisinde oldukları söylenebilir. Bu teorik bakış açısına dayanarak çalışmış olduğu örgüte yönelik hakkaniyet algısı yüksek olan çalışanların dolayısıyla pozitif tutumlardan biri olan iş tatminini yaşayacakları ve bunu gözlenen bir sonuca yani örgütsel vatandaşlık davranışı göstererek örgüte yanıt verecekleri önerilmektedir. Buna göre geliştirilen araştırmanın birinci önermesi şu şekildedir;

Önerme 1: Örgütsel adalet ile örgütsel vatandaşlık davranışları arasındaki pozitif yöndeki ilişki iş tatmini aracılığı ile gerçekleşmektedir.

\section{Aracı Değişken: Örgütsel Bağlılık}

Örgütsel bağlıık, çalışanların kurumlarıyla istikrarlı bir ilişki kurma arzusunu ve bu ilişkileri güvenli bir ortamda sürdürmek için fedakârlık yapma isteklerini ifade eder (Anderson ve Weitz, 1992). Daha kapsamlı bir ifadeyle, bilinçli bir tutum olan örgütsel bağıılı, çalışanın işini benimseyip, sadakat gösterip, örgütsel hedeflere ve değerlere duygusal bağlılık göstermesi olarak tanımlanabilir (Becker, 1960; Buchanan, 1974).

Örgütsel bağlılık; duygusal bağlılık, devam bağlılığı ve normatif bağlılık olmak üzere üç temel bileşenden oluşur. Duygusal bağlılık; çalışanın yaptığı işe veya örgütüne karşı duyduğu duygusal bağlılığı ifade eder. Devam bağııı̆ı; çalışanların örgütlerinden ayrılmanın maliyetini dikkate aldıklarında örgütlerinde kalmaya ihtiyaçlarının olduğunu düşünmeleri yönündeki bir bağlılığı açıklar. Normatif bağlılık; çalışanların bunun etik temelli bir sorumluluk olduğunu düşündükleri için işi bırakmamaları gerektiğini hissetmelerinden dolayı oluşan bir örgütsel bağlılık tipidir (Allen ve Meyer, 1990; Meyer, Allen ve Smith, 1993).

Sosyal Mübadele Teorisi bağlamında düşünüldüğünde kendilerinin haklarını gözeten, eşitlikçi ve liyakata göre ödül, ilişki ve süreç adaleti sağlayan bir kurumda çalışmak çalışanların bu kurumlarda kalmalarını motive edecek ve başka bir örgüt arayışından uzaklaştırarak risk almalarını engelleyecektir. Başka bir ifadeyle, örgütsel adalet algısı, çalışanları örgütlerine bağlanmaları yönünde motive eden ve örgütteki sürdürülebilirliklerini besleyen bir algıdır. Bu teorik bakış açısına dayanarak örgütsel adalet algısı yüksek olan çalışanların pozitif tutumlardan biri olan örgütsel bağlılık tutumu yaşayacakları, dolayısıyla örgütlerin lehine pozitif davranışlardan biri olan örgütsel vatandaşlık davranışları sergileyecekleri önerilmektedir. Buna göre geliştirilen araştırmanın ikinci önermesi şu şekildedir;

Önerme 2: Örgütsel adalet ile örgütsel vatandaşlık davranışları arasındaki pozitif yöndeki ilişki örgütsel bağlılık aracılığı ile gerçekleşmektedir.

\section{Düzenleyici Değişken: Bilinçli Farkındalık}

Bilinçli farkındalık, geçmiş veya gelecek tarafından etkilenmeden, şu an için tam bir farkındalık veren bir bilinç halidir (Thondup, 1998). Başka bir ifadeyle, bilinçli farkındalık, kişinin iç ve dış dürtülere rağmen şimdiki zamana odaklanmasıdır (Dane, 2011). Literatürde bilinçli farkındalıkla ilgili yapılan tanımlara bakıldığında bu tanımların ortak yanı; bilinçli farkındalığın içinde bulunulan olumlu veya olumsuz şartların farkında olmak ve tüm koşullara rağmen istekli dikkatlilik göstermek olduğunu söylemeleridir (Brown ve Ryan, 2003; Develi, Güğerçin ve İplik, 2017).

Uzun yıllardır klinik psikoloji alanında depresyon ve anksiyete hastalarının tedavisinde kullanılan bilinçli farkındalığın pozitif etkileri iş hayatında da keşfedilmeye başlanmıştır (Hyland, Lee ve Mills, 2015). Yönetim ve organizasyon alanındaki yabancı literatür de bilinçli farkındalığın işyerlerinin işleyişi üzerinde etkili olduğunu göstermektedir (Glomb, Duffy, Bono ve Yang, 2011). Örneğin, bilinçli farkındalığın işgörenlerin çalışma saatleri içinde kendilerini yapmaktan alıkoyamadıkları, kendilerine ve işlerine yararlı olmayan faaliyetlerin azaltılmasına yardımcı olduğu tespit edilmiştir (Brockner ve Wiesenfeld, 2016).

Sosyal Bilişsel Teori bireylerin davranışları üzerindeki kontrol ve çeşitli mekanizmaların (öz düzenleyici, öz kontrol) harekete geçirilip geçirilmemesi yönünde insanın özgür iradesini kullanma şeklini vurgulamaktadır. Bu yönüyle bireylerin kendi öz farkındalıklarının bilincinde olduğu ve bu farkındalıkları kapsamında davranışlar sergiledikleri söylenebilir. Ancak her ne kadar ideal olan durumda bireylerin aynı düzeyde farkındalıklara sahip oldukları düşünülse de farkındalık düzeyleri bireyden bireye farklılık göstermektedir. Başka bir ifade ile her ne kadar insan davranışlarının Sosyal Mübadele Teorisine göre çeşitli algı ve tutumların bir sonucu olduğu düşünülse de Sosyal Bilişsel Teoriye göre bu algı ve tutumların farkındalığını ortaya çıkarabilecek mekanizmaların harekete geçirilmesi insan unsuruna bağlıdır. Dolayısıyla örgüt her ne kadar adaletli bir ortam sağlasa da çalışan bu adaletli durumu fark etmediği sürece örgütsel adalet gibi çeşitli pozitif algıların pozitif tutumlara (iş tatmini, örgütsel bağlılık) yol açması, dolayısıyla pozitif davranışların ortaya çıkması (örgütsel vatandaşlık davranışları) öngörülmemektedir. Bu açıklamalar ışığında geliştirilen önermler şu şekildedir;

Önerme 3: Örgütsel adalet algısının iş tatmini aracılığı ile örgütsel vatandaşlık davranışları üzerindeki pozitif etkisi bilinçli farkındalık düzeyi yüksek olan çalışanlarda ortaya çıkmaktadır.

Önerme 4: Örgütsel adalet algısının örgütsel bağlıık aracılığı ile örgütsel vatandaşlık davranışları üzerindeki pozitif etkisi bilinçli farkındalık düzeyi yüksek olan çalışanlarda ortaya çıkmaktadır. 


\section{Şekil 1: Kavramsal Model}

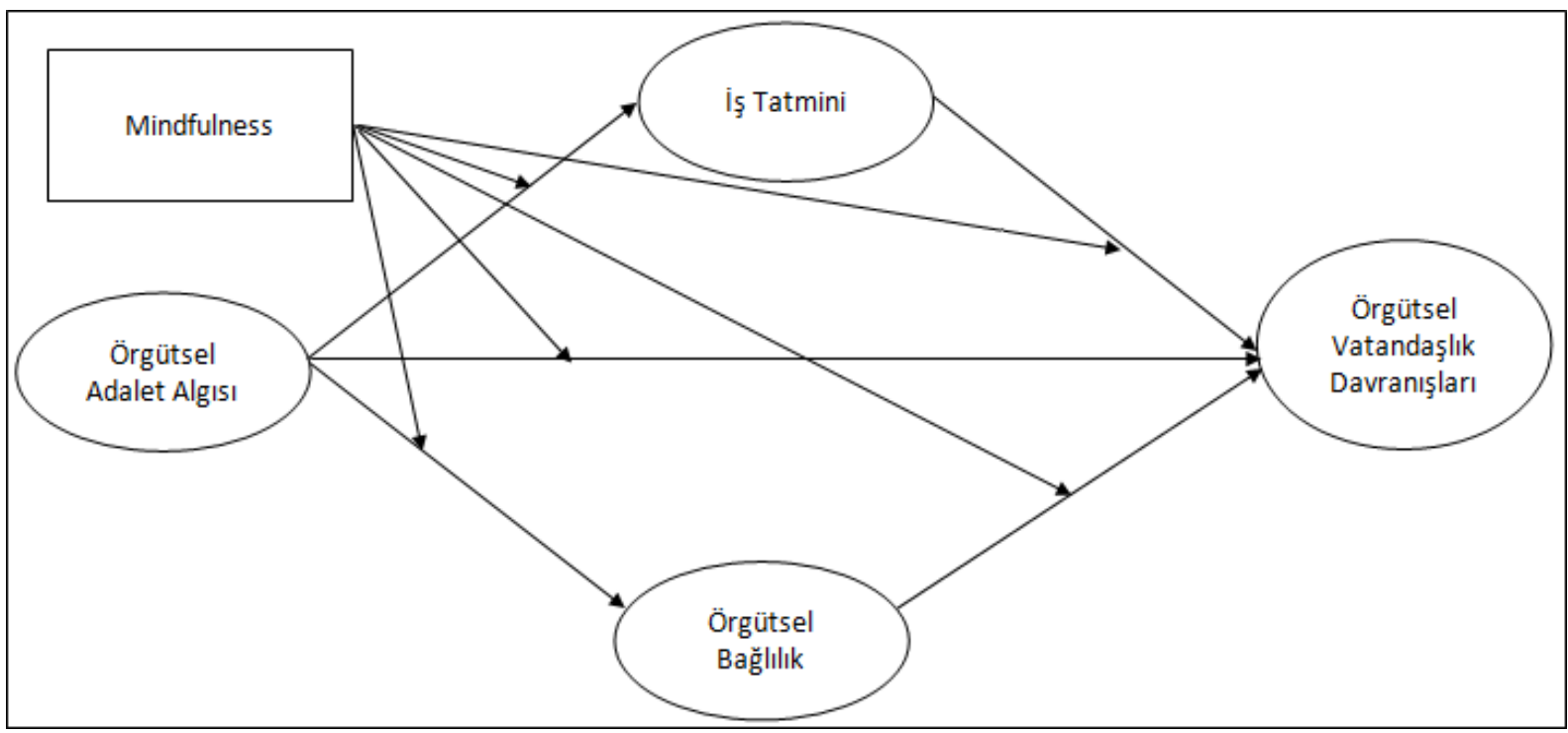

\section{SONUÇ}

Bu çalışmada, Sosyal Bilişsel Teori (Bandura, 2001) ve Sosyal Mübadele Teorisi (Blau, 1964) temelinde, örgütsel adalet algısı ve örgütsel vatandaşlık davraşı ilişkisinde iş tatmini ve örgütsel bağlıı̆ın aracılık etkisi ve tüm bu ilişkilerde bilinçli farkındalığın şartlı değişken etkisi ele alınmıştır. Kültürler arası kıyaslamalı bir makalenin fikir gelişim aşamasını temsil eden bu çalışmadaki kavramsal modeli oluşturan her bir kavram değişken niteliği taşımaktadır. Başka bir ifade ile ilgili yazında bu kavramları ölçmek için gerekli güvenilirlik ve geçerliliği yapılmış olan ölçüm araçları bol miktarda mevcuttur.

Çalışmada söz konusu teorilerin kılavuzluğu ve ilgili literatürden yola çıkılarak, SPSS programıyla ve bu program için geşiştirilen PROCESS makrosu üzerinden aracılığa düzenleyicilik (moderated mediation) ilişkisinin incelenebileceği kavramsal bir model geliştirilmiştir. Bu model ile algı, tutum ve davranış süreci bilinçli farkındalığın şartlı değişken etkisi altında ampirik bir araştırmayla test edilebilecektir.

Geliştirilen bu araştırma modelinin uygulanması durumunda, mevcut literatüre iki yönüyle katkı sağlayacağı düşünülmektedir. Bunlardan ilki; durumsal indirekt etki (moderated mediation) analizi kullanılarak bilinçli farkındalığın düzenleyici rolünü belirlemektir. ỉkincisi ise; mevcut yazında zaten oturmuş olan ilişkilerin mevcudiyetini moderatör değişken sayesinde sorgulamaktır. Diğer yandan modelin testinin insan kaynakları yönetimi ve örgütsel davranış alanındaki uzman ve profesyonellerin çalışanları seçme, yerleştirme ve motive etme yönündeki motivatörleri belirleme ve yeni stratejiler geliştirmeleri yönünde bir farkındalık sağlayacağı düşünülmektedir.

Her ne kadar bu çalışma güçlü teorik temeller ve kapsamlı bir alan yazın taraması neticesinde ortaya çıkmış olsa da bu araştırmanın en önemli kısıtı ampirik sonuçlar ve bulgulardan yoksun olmasıdır. Bu bağlamda gelecekteki araştırmacıların bu modeli ampirik bir araştırma dizaynında ele alıp test etmeleri ve farklı teorik bakış açıları ile değerlendirmeleri önerilmektedir.

\section{KAYNAKLAR}

Allen, N. J., Meyer, J. P. (1990). The measurement and antecedents affective, continuance and normative commitment to the organization. Journal of applied psychology, 63(1), 1-18

Anderson, E., Weitz, B. (1992). The use of pledges to build and sustain commitment in distribution channels. Journal of marketing research, 18-34.

Aryee, S., Budhwar, P. S., Chen, Z. X. (2002). Trust as a mediator of the relationship between organizational justice and work outcomes: test of a social exchange model. Journal of organizational behavior, 23(3), 267-285.

Azırı, B. (2011). Job satisfaction: a literature review. Management research \& practice, 3(4), 77-86

Bahn, D. (2001). Social learning theory: its application in the context of nurse education. Nurse education today, $21(2), 110-117$.

Bandura, A. (2001). Social cognitive theory: an agentic perspective. Annual review of psychology, 52(1), 1-26.

Bandura, A. (2002). Social cognitive theory in cultural context. Applied psychology, 51(2), 269-290.

Becker, H. S. (1960). Notes on the concept of commitment. American journal of sociology, 66(1), 32-40. 
Bies, R. J., Moag, J. S. (1986). Interactional justice: communication criteria for fairness. B.H. Sheppard (eds), Research on Negotiation in Organizations, Greenwich: JAI Press, ss. 43-55.

Blau, P. M. (1964). Exchange and power in social life. First Edition, New York, NY: John Wiley\&Sons.

Brockner, J., Wiesenfeld, B. M. (2016). Self-as-object and self-as-subject in the workplace. Organizational behavior and human decision processes, 136, 36-46.

Brown, K. W., Ryan, R. M. (2003). The benefits of being present: mindfulness and its role in psychological well-being. Journal of personality and social psychology, 84(4), 822-848.

Buchanan, B. (1974). Building organizational commitment: the socialization of managers in work organizations. Administrative science quarterly, 533-546.

Chambers, B. A. (2002). Applicant reactions and their consequences: review, advice, and recommendations for future research. International journal of management reviews, 4(4), 317-333.

Colquitt, J. A., LePine, J. A., Piccolo, R. F., Zapata, C. P., Rich, B. L. (2012). Explaining the justice-performance relationship: trust as exchange deepener or trust as uncertainty reducer?. Journal of applied psychology, 97(1), 1.

Cropanzano, R., Mitchell, M. S. (2005). Social exchange theory: an interdisciplinary review. Journal of management, 31(6), 874-900.

Dane, E. (2011). Paying attention to mindfulness and its effects on task performance in the workplace. Journal of management, 37(4), 9971018.

Davis, K., Nestrom, J.W. (1985). Human behavior at work: organizational behavior. 7 edition, McGraw Hill, New York.

Develi, A., Güğerçin, S., İplik, E. (2017). Bilinçli farkındalık ve örgütsel stres kaynakları: banka çalışanları örneği. Social sciences studies journal (SSSJournal), 3(2), 44-51.

Emerson, R. M. (1976). Social exchange theory. Annual review of sociology, 2(1), 335-362.

Glomb, T. M., Duffy, M. K., Bono, J. E., Yang, T. (2011). Mindfulness at work. Research in personnel and human resources management, 30, 115-157.

Hackman, J. R., Oldham, G. R. (1976). Motivation through the design of work: test of a theory. Organizational behavior and human performance, 16(2), 250-279.

Hyland, P. K., Lee, R. A., Mills, M. J. (2015). Mindfulness at work: a new approach to improving individual and organizational performance. Industrial and organizational psychology, 8(4), 576-602.

Judge, T. A., Colquitt, J. A. (2004). Organizational justice and stress: the mediating role of work-family conflict. Journal of applied psychology, 89(3), 395

Koys, D. J. (2001). The effects of employee satisfaction, organizational citizenship behavior, and turnover on organizational effectiveness: a unit-level, longitudinal study. Personnel psychology, 54(1), 101-114.

Luo, Y. (2009). Are we on the same page?: justice agreement in international joint ventures. Journal of world business, 44(4), 383-396.

Meyer, J. P., Allen, N. J., Smith, C. A. (1993). Commitment to organizations and occupations: extension and test of a three-component conceptualization. Journal of applied psychology, 78(4), 538.

Organ, D. W. (1990). The motivational basis of organizational citizenship behavior. Research in organizational behavior, $12(1), 43-72$.

Podsakoff, P. M., MacKenzie, S. B., Paine, J. B., Bachrach, D. G. (2000). Organizational citizenship behaviors: a critical review of the theoretical and empirical literature and suggestions for future research. Journal of management, 26(3), 513-563.

Schnake, M. E., Dumler, M. P. (2003). Levels of measurement and analysis issues in organizational citizenship behaviour research. Journal of occupational and organizational psychology, 76(3), 283-301.

Smith, C. A., Organ, D. W., Near, J. P. (1983). Organizational citizenship behavior: its nature and antecedents. Journal of applied psychology, 68(4), 653.

Spector, P. E. (1997). Job satisfaction: Application, assessment. Causes and consequences. Thousand Oaks, CA: Sage Publications.

Thondup, T. (1998). The healing power of mind: simple meditation exercises for health, well-being, and enlightenment. Shambhala Publications.

Vroom, V. H. (1964). Work and motivation. John Wiley and Sons, New York.

Wang, L., Hinrichs, K. T., Prieto, L., Howell, J. P. (2013). Five dimensions of organizational citizenship behavior: comparing antecedents and levels of engagement in China and the US. Asia pacific journal of management, 30(1), 115-147. 